\title{
Contra la mort: exaltación de la pura alegría vital
}

Jordi Pàmias

En el prólogo de Les roses de Ronsard (2009), Pere Rovira subraya el aspecto artesanal de la poesía, el oficio del poeta, como elemento imprescindible de una obra con validez estética. Y afirma que tiene poca relación con la libertad. Según él, la libertad artística, mal entendida, ha dado lugar, en algunos casos, a productos ininteligibles y a un galimatías crítico nefasto — sobre todo en los primeros treinta años del siglo XX.

Pere Rovira analiza muy bien la poesía de Pierre de Ronsard (primera y segunda parte de los Sonets per a Helena), en el contexto del Renacimiento (siglo XVI). Y se siente identificado con ella por la claridad, la gracia, la delicadeza sutil y los toques de humor que detecta en la obra del gran poeta francés.

$\mathrm{Su}$ influencia se nota en muchos aspectos formales del libro Contra la mort, sobre todo en el cultivo frecuente del soneto (aunque se permite alguna licencia en el uso de la rima consonante o en el esquema métrico de Petrarca, ya que a menudo recurre al soneto inglés). Hay que señalar también la notable presencia del verso alejandrino. Y es un traductor excepcional (fiel a Ronsard en el espíritu y en la forma), como demostró ya en la magnífica versión al catalán de Vint-i-cinc flors del mal, de Charles Baudelaire (2008).

\section{CONTRA LA MORT. POEMA INICIAL}

En "Records de l'altre món", el poeta indica el punto de partida. Nos habla desde la muerte: “(...) Jo, a l'altre costat / de la frontera fosca; tu dintre de la vida". La persona a quien se dirige vive aún. Hay, pues, una diferencia ontológica (la nada contra el ser), que sólo la creación poética puede anular, en un arriesgado salto de la imaginación: 
Em trobaràs per casa, plorant en un racó perquè no et puc tocar, fantasma del desig d'estar amb tu, inacabable...

La última estrofa es la culminación de una fantasía audaz. Toda la fuerza del poeta se concentra en estos versos:

Vindràs com una llum negra i blanca, impossible, com si fossis la lluna del país dels difunts, i els meus ossos sabran que tornem a estar junts, i ja no tindran fred en el seu clot horrible.

Estos "Records de l'altre món” cumplen la misma función de una obertura en el campo de la ópera. Es un poema que anticipa el argumento, en una difícil y velada síntesis, y marca el tono de la obra entera. El poeta nos avisa: olvidad la fría lógica, entrad en el mundo de la pura, deslumbradora creación poética. Aceptad la insuficiencia de la razón e intuid la verdad profunda de un amor más allá de la muerte. Como dice Francisco de Quevedo, los huesos

serán ceniza, mas tendrán sentido, polvo serán, mas polvo enamorado.

'Apunts' (NuEVE POEMAS)

Si, en el poema inicial, la creación literaria refleja la soterrada pugna entre la vida y la muerte, esta serie se abre con la maravilla ambigua de la obra de arte. El poeta se siente hechizado ante la joven del retrato, que tiene un libro en las manos. Mientras "va passant les planes, jo li busco les cuixes", confiesa. Y añade: "et torno a enganyar amb ella". Se trata, pues, de un triángulo imaginario, formado por el poeta, la mujer real y la enigmática "noia del retrat". El erotismo y el arte, en una delicada armonía.

En el segundo poema, "El nom", triunfa el sortilegio de la palabra. Aparece "el teu nom de lluna negra", dice, refiriéndose a la mujer amada. El secreto es imposible, "perquè tot el que escric diu el teu nom" —el cual cumple, así, una función protectora.

En el tercero, la mira de hito en hito, al margen del nombre y de cualquier vaguedad. Y se fija en el cuello, que "és fresca pell de pruna y només pot tenir gust de joventut". Al fin, le suplica:

No l'insultis amb sedes i fulards, si el teu setembre, amor, s'ha de dir març. 
En "Els ulls" hay un juego de palabras: "salina llum dels dinou anys y celístia clement" (confluyen en Celina: el nombre real de la mujer amada). Contra la alegría juvenil, avanza "la por de la tristesa en una cara". A la diferencia de edad hay que añadir, en el hombre, "els tels dels desenganys". Él se imagina el futuro y ve, en la mirada de ella,

un llamp de joventut enamorada

que estellarà la porta de l'espant.

Sin duda, "Mirant la mar del delta" es uno de los mejores poemas del libro. Encontramos en él un espacio concreto, bien conocido por el poeta: "la mar inacabable, la mar consoladora" en la hora del crepúsculo, "mentre es dessagna el dia que se’n va". La contemplación del mar, "com si fos una música que es veu", le infunde una paz secreta y le permite

(...) quedar-nos sols

fins que la vida nostra ens enamora.

Triunfo absoluto de la vida. Los ojos, mirando el mar, ya "no hi veuran la mort ni l'infinit".

El aliento vitalista continúa en los poemas siguientes, hasta el fin de la sección.

En "Lestiu" domina "la brisa d'aquest vespre (...) vora la mar".

Hay, en "La boca", "sempre un paradís / ofert en els seus llavis": de nuevo, la visión fáustica, el puro goce de la vida. En "Maternitat", "és la fruita madura que no se sap marcir".

Y, en "Albada", el hombre participa plenamente en esta embriaquez de los sentidos, que le permite olvidar el paso del tiempo:

acosta’t amb la llengua a la delícia, llisca per la rosada pell de l'alba, llepa la vida estesa, xucla, salva el segle dels instants (...)

'Arbres'

En una calculada simetría, encontramos la "Primera rosa" -ejemplo de delicadezaflanqueada por dos árboles, todavía jóvenes ("El llorer” y "Els ametllers"), y dos más vigorosos: "Oliver mil.lenari" y "Avellaners".

El árbol más antiguo es ensalzado en un poema formado por alejandrinos: versos largos, musicales, de una rotundidad que Pere Rovira no confunde nunca con la retórica. Es un poema dominado por el viento del delta, con "les seves ales d'immens ocell marí: 
el vent enjogassat, el vent blau de la mar". Sin duda, un magnífico poema, un verdadero canto al olivo milenario.

Tiene puntos de contacto con el último poema de la serie: "Avellaners", un soneto impecable, de una sobriedad que se alía con la emoción profunda, contenida. Ya al principio, dice: "el meu padrí / cavava avellaners de sol a sol / per enterrar les ganes de morir”. Y continúa:

De nit, mirava el foc, bevia vi

i fumava el tabac del desconsol

El poeta se siente solidario con los antepasados, en el salto de una generación a otra: "gràcies a ell, vivim. Que quedi escrit".

El verso decasílabo (catalán), de una rara fluidez, reforzada por algunos encabalgamientos, es un ejemplo de la maestría de Pere Rovira en el poema "El llorer", formado por seis cuartetos, con el esquema ABAB. Llega "l'hivern de les grans neus" y el árbol "sense verdor ni força, / semblava, de tan sec, palla de jonc". Pero triunfa el mes de abril, y el laurel se humaniza:

l'esquelet del llorer es posava a riure de pessigolles si el movia el vent.

\section{'Homenatges'}

Se inicia con la traducción de un poema de Paul Verlaine: "Cavaller emmascarat...", en estrofas de alejandrinos pareados. Y continúa con la evocación de un amigo poeta (sin nombrarlo), que se quitó la vida:

va buscar la finestra més alta.

Va fugir de l'agost mort de fred.

Poema intenso, conmovedor, con un gran acierto: el uso constante del eneasílabo (tres toques de tambor, en cada verso).

En el soneto "A Màrius Torres", el cuarto verso evoca un famoso poema del médico leridano: "Ara que el braç potent de les fúries aterra..." Alude a la enfermedad y al conflicto bélico:

ni la guerra del pit ni la d'Espanya 
Torres había ingresado en un sanatorio antituberculoso, donde murió. Y la voz del poeta, "sempre jove, fidel, alta", se apaga con una palabra muy significativa: Mahalta, la mujer amada.

Tras la poesía, la música. En el "Trio en do menor", para violín, violoncelo y piano, de Haydn, Pere Rovira ve "un cor apedregat, un xiscle d'enyorança" y, rompiendo "l'harmonia funeral, l'alta rialla d'aigua del piano".

En un balanceo muy hábil, siguen tres poemas ligeros: "Dedicatòria" (texto muy personal), "A la peresa": un juguetón poema alegórico, en torno a uno de los siete pecados capitales, y "Brindis": elogio del vino, en versos pareados, que por el tono, casi dionisíaco, nos recuerda a Omar Kheyyam:

i continua el seu prodigi el vi,

deixant-nos oblidar que hem de morir.

En cambio, el tono es más grave en los tres últimos poemas de la serie: "Amics vells", "Feréstec" y "Sant Pere".

"Feréstec" es un poema claramente relacionado con "Avellaners"; incluso hay algunas similitudes en la manera de presentar al padrí, que "encenia el caliquenyo" y "domava la pobresa a cops d'aixada".

"Sant Pere" es una sobria y dolorida evocación del padre muerto. Así pues, al fin de la serie, el homenaje se dedica a las raíces familiares más próximas.

\section{'SEMPRE'}

Es la sección más larga del libro. Consta de 21 poemas. Se entrecruzan los temas de las secciones anteriores, elevados a la máxima potencia. Con una lúcida audacia, Pere Rovira juega aquí todas sus bazas. La carga humana y el rigor estético armonizan muy bien en un conjunto de poemas - que muestran una notable variedad formal.

Hay ocho sonetos: tres a la manera italiana, según Petrarca (dos cuartetos y dos tercetos) y cinco según el modelo inglés (tres cuartetos y dos versos pareados).

Tres poemas están formados por cuartetos de versos decasílabos, con rima consonante en dos casos (ABBA), y en el otro por alejandrinos, con rima asonante.

En cinco hay sólo versos pareados (la mayoría, alejandrinos).

En el poema "L'ànima mortal" sorprende la variedad métrica, que da una extraña ligereza a los versos. En "Secretament" alternan el alejandrino y el hexasílabo.

Hay tres poemas consecutivos con un ritmo vivaz. Los dos primeros son "Cançó de la tristesa vella" y "Cançó teva". Y el tercero, "L'arena", es una especie de pequeño soneto invertido. En los tres hay versos cortos, que apuntan a un concepto lúdico de la poesía. 
Llama la atención la intensidad expresiva de los poemas con que se inicia la serie: "Sempre" y "París amb tu". Por otra parte, hay que destacar la voluntad de síntesis en los tres últimos.

En la noche de "Fuga" encontramos "l'altra música primera", de que nos habla Fray Luis de León en la "Oda a Franciso Salinas", y "la celístia d'un nom / que l'espera cantant". La repetición de "Feliç el que..." recuerda la estructura de las Bienaventuranzas cristianas. En "La veu" hay unas apasionadas preguntas:

¿Què ens diria una veu que fos veu de tots dos?

¿Es creuria que és nova i diria l'amor

en plural singular?

Y, en un verso impresionante, nos habla de

Les veus, vi de les ànimes, bevent-se l'una a l'altra...

Hay un poema que es un claro homenaje a Ronsard: “Quan ja siguis molt vella”. Pere Rovira nos dice que

la llum de primavera

(...) no te l'apagaran

la por ni la tristesa, $i$ aniràs a dormir

somrient a les ombres. I dormiràs amb mi.

En el último poema, "Els dons", la entrega del amor se concentra, hábilmente, en el juego de los versos pareados (yo y tú, cara a cara):

i amb les puntes dels dits deslliguem el desmai;

el plaer és una llengua que no ens ha mentit mai.

También hay que citar el poema "Eros matinal", con el mismo recurso: la gracia o el combate de los versos pareados. El poeta sintió, un día, la proximidad de la muerte: "el bram afamat de la nit, y els seus tentacles molt a prop del meu pit"; por ello, detesta la oscuridad. No le puede consolar un cielo que "ni és cel ni és blau" (clara alusión a un verso de Bartolomé Leonardo de Argensola). El vigor simbólico del poema alcanza el punto más alto cuando confiesa:

(...) Però fas néixer l'alba

en el teu cos amant, i ets claredat que em salva.

En estos versos se encuentra el sentido último del libro. Ciertamente, fue escrito contra la mort. Y todos los poemas son un alegato lúcido, irrefutable, a favor del com- 
promiso amoroso, una exaltación de la pura alegría vital, sin ninguna clase de reservas -aunque el cuerpo, inevitablemente, envejezca. Es el mensaje radical del hombre y del poeta: "a tot o res", como dijo Carles Riba en un soneto de Salvatge cor. 